International Journal of Current Advanced Research

ISSN: O: 2319-6475, ISSN: P: 2319 - 6505, Impact Factor: SJIF: 5.995

Available Online at www.journalijcar.org

Volume 6; Issue 4; April 2017; Page No. 3139-3143

DOI: http://dx.doi.org/10.24327/ijcar.2017.3143.0204

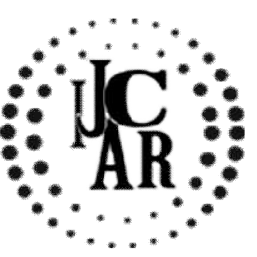

Research Article

\title{
FEAR LEVELS FOR DIFFERENT DENTAL PROCEDURES AMONG GENERAL POPULATION
}

\section{Suhas Manoharan and Jayalakshmi*}

Saveetha Dental College and Hospitals No.162, PH road, Chennai-600077

A R T I C L E I N F O

Article History:

Received $19^{\text {th }}$ January, 2017

Received in revised form $13^{\text {th }}$ February, 2017

Accepted $16^{\text {th }}$ March, 2017

Published online $28^{\text {th }}$ April, 2017

\section{Key words:}

Different Dental, General Population

\begin{abstract}
A B S T R A C T
Aim and Objective: To assess the fear level of patients for different dental treatments. Background: Studies reveal that One in four people have fear of dental treatments or visiting the dentist. Women tend to report more dental fear than men, and younger people tend to report being more dentally fearful than older individuals.

Conclusion: It is essential for a dentist to be familiar with the reasons or stimuli that evoke fear among the patients in order to establish a successful practice.
\end{abstract}

Copyright $(2017$ Suhas Manoharan and Jayalakshmi. This is an open access article distributed under the Creative Commons Attribution License, which permits unrestricted use, distribution, and reproduction in any medium, provided the original work is properly cited.

\section{INTRODUCTION}

Modern day dentistry consists a wide range of procedures which may be cosmetic, reparative or restorative. Suchprocedures evoke wide range of fear among the patients. Fear is the emotion aroused by danger or pain, whether real or imagined. When a fear becomes irrational and uncontrollable, it becomes a phobia. Fear is vital response to physical and emotional danger which is essential to protect oneself from legitimate threats. Fear, especially in the dental environment, commonly known as dental fear has a psychological and physiological etiology. Fear is also a learned response from observing family, friends, society, and role models. Dental fear may develop as a result of a previous traumatic experience in a non-dental or dental context. ${ }^{[1][4]}$ For example, bad experiences with doctors or hospital environments may lead people to fear white coats and smell of antiseptics .Dental fear is associated with reduced treatment, as they are related with cancellation of appointments and act as a barrier for obtaining treatment. Hence, a survey was conducted to find out the fear level of different dental procedures among a random group of 100 people.

\section{MATERIALS AND METHODS}

In this research, a survey was conducted among a random group of 400 people which consisted of 168 males and 232 females. The age group of the participants varied from 15 years to 73 years.

*Corresponding author: Suhas Manoharan

Saveetha Dental College and Hospitals No.162, PH road, Chennai-600077

\section{Scaling}

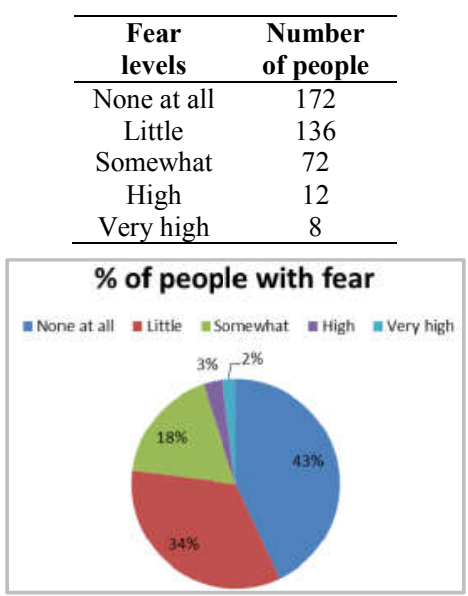

Reason for fear

\begin{tabular}{cc}
\hline Reason for fear & Number of people \\
\hline Sight and smell of a dentist & 52 \\
Sitting on a dental chair & 48 \\
Sound of handpiece & 76 \\
Sensitivity of teeth caused & 196 \\
during the treatment & \\
\hline
\end{tabular}

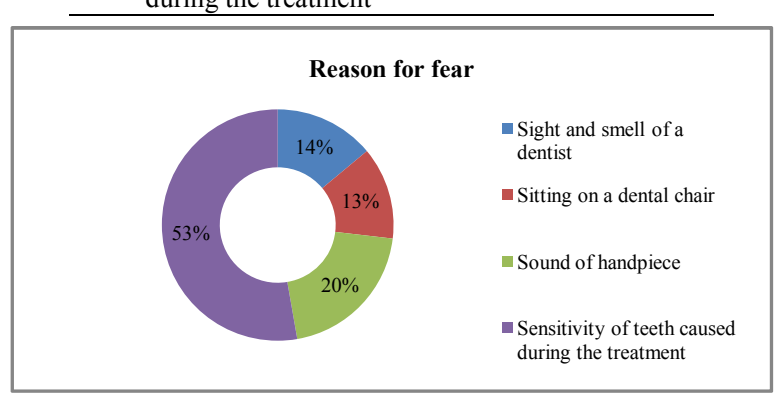




\section{Data analysis}

The survey was conducted using a self-made questionnaire partly based on kleinknecht fear survey ${ }^{[2]}$. From the survey, the following data was collected.

\section{Tooth extraction}

\begin{tabular}{cc}
\hline Fear levels & Number of people \\
\hline None at all & 112 \\
Little & 120 \\
Somewhat & 108 \\
High & 48 \\
Very high & 4 \\
\hline
\end{tabular}

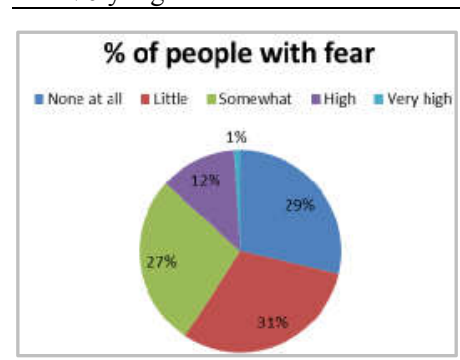

\section{Reason for fear}

\begin{tabular}{cc}
\hline Reason for fear & Number of people \\
\hline Sight and smell of a dentist & 32 \\
Sitting on a dental chair & 44 \\
Sight of syringe or needle & 120 \\
Sight of forceps & 60 \\
Pain & 208 \\
Bleeding or sight of blood & 112 \\
\hline
\end{tabular}

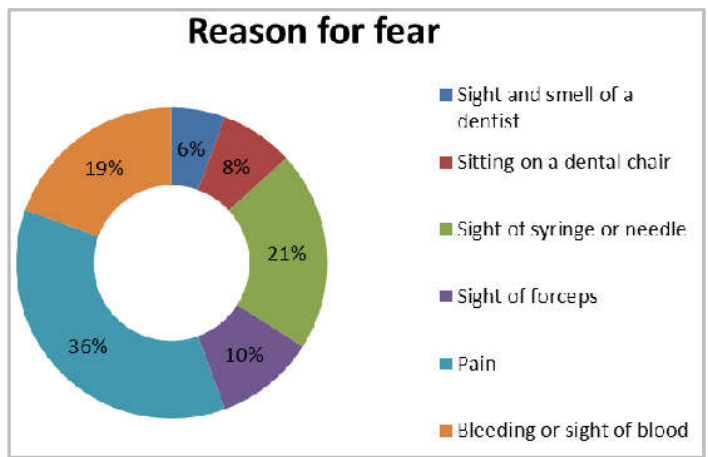

\section{Root canal treatment}

\begin{tabular}{cc}
\hline Fear levels & Number of people \\
\hline None at all & 160 \\
Little & 96 \\
Somewhat & 100 \\
High & 32 \\
Very high & 12 \\
\hline
\end{tabular}

\section{$\%$ of people with fear}

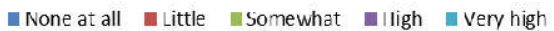

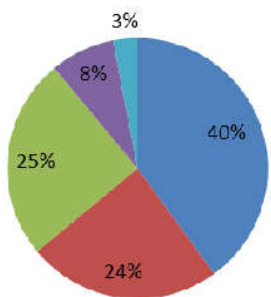

\section{Reason for fear}

\begin{tabular}{cc}
\hline Reason for fear & Number of people \\
\hline Sight and smell of a dentist & 20 \\
Sitting on a dental chair & 18 \\
Sight of handpiece & 64 \\
Sight of syringes & 120 \\
Sight of specialized dental instruments & 188 \\
used to carry out root canal treatment \\
like files, spreader etc
\end{tabular}

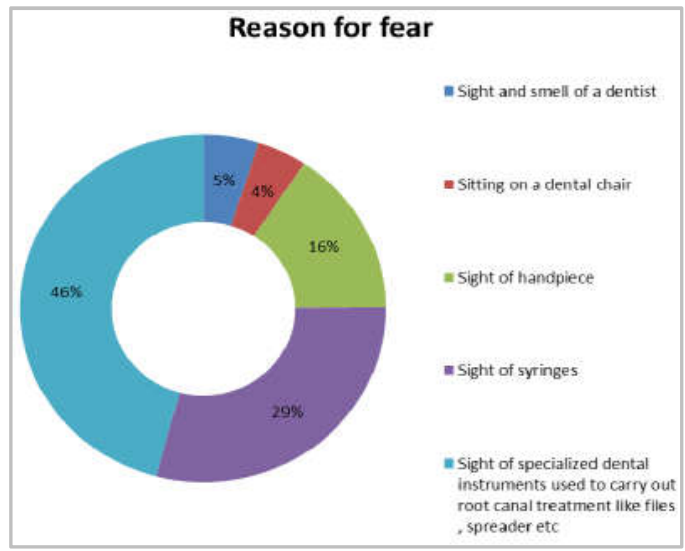

Dental implants

\begin{tabular}{cc}
\hline Fear levels & Number of people \\
\hline None at all & 188 \\
Little & 64 \\
Somewhat & 64 \\
High & 68 \\
Very high & 16 \\
\hline
\end{tabular}

$\%$ people with fear

None at all Little $=$ Somewhat $\quad$ High $=$ Very high

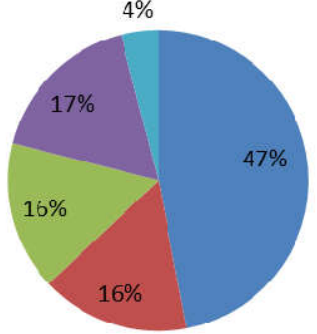

\section{Reason for fear}

\begin{tabular}{cc}
\hline Reason for fear & $\begin{array}{c}\text { Number of } \\
\text { people }\end{array}$ \\
\hline Sight and smell of a dentist & 12 \\
Sitting on a dental chair & 44 \\
Sight and sound of handpiece & 48 \\
Sight of syringes & 80 \\
Surgical method of treatment & 180 \\
\hline
\end{tabular}

\section{Reason of fear}

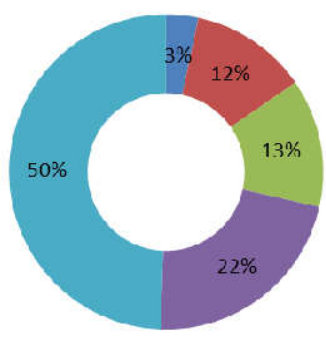

Sight and smell of a dentist

- Silling un a denlal chair

- Sight and sound of handpiece

- sight of syringes

a Surgical method of treatment 


\section{Dental restorations such as fillings}

\begin{tabular}{cc}
\hline Fear levels & $\begin{array}{c}\text { Number of } \\
\text { people }\end{array}$ \\
\hline None at all & 176 \\
Little & 116 \\
Somewhat & 76 \\
High & 24 \\
Very high & 8 \\
\hline
\end{tabular}

\section{$\%$ of people with fear}

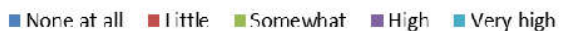

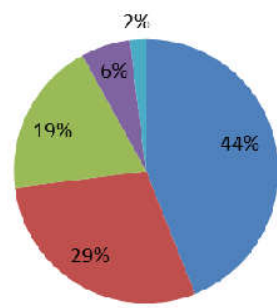

Reason for fear

\begin{tabular}{cc}
\hline Reason for fear & Number of people \\
\hline Sight and smell of a dentist & 16 \\
Sitting on a dental chair & 36 \\
Sight and sound of handpiece & 68 \\
Sensitivity of teeth caused during & 212 \\
treatment &
\end{tabular}

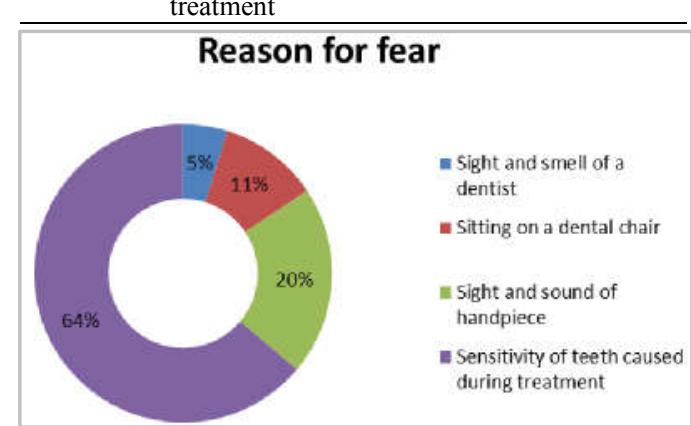

Orthodontic treatment

\begin{tabular}{cc}
\hline Fear levels & Number of people \\
\hline None at all & 160 \\
Little & 96 \\
Somewhat & 100 \\
High & 32 \\
Very high & 12 \\
\hline
\end{tabular}

\section{$\%$ of people with fear}

= None at all = Little $=$ Somewhat $=$ High $=$ Very high

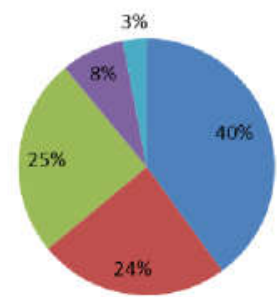

Reason for fear

\begin{tabular}{cc}
\hline Reason for fear & $\begin{array}{c}\text { Number of } \\
\text { people }\end{array}$ \\
\hline Sight and smell of a dentist & 12 \\
Sitting on a dental chair & 20 \\
Sight of other instruments & 64 \\
Pain & 172 \\
\hline
\end{tabular}

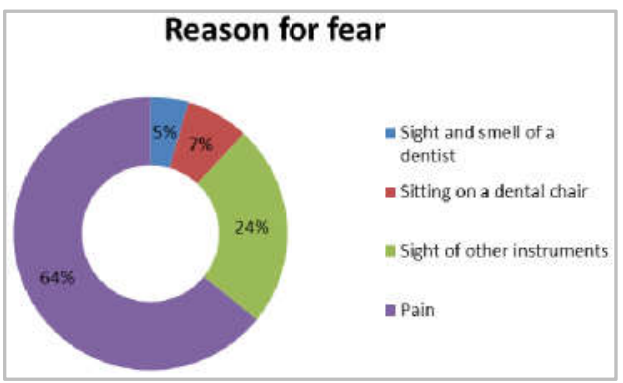

Local anesthesia adminstration

\begin{tabular}{cc}
$\begin{array}{c}\text { Fear } \\
\text { levels }\end{array}$ & $\begin{array}{c}\text { Number of } \\
\text { people }\end{array}$ \\
\hline None at all & 140 \\
Little & 156 \\
Somewhat & 52 \\
High & 44 \\
Very high & 8 \\
\hline
\end{tabular}

$\%$ of people with fear

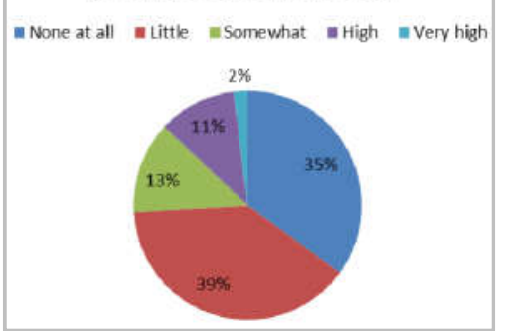

Reason for fear

Reason for fear $\begin{gathered}\text { Number of } \\ \text { people }\end{gathered}$

\begin{tabular}{cc}
\hline Sight and smell of a dentist & 12 \\
Sitting on a dental chair & 40 \\
Sight of syringe & 148 \\
Pain & 164 \\
\hline
\end{tabular}

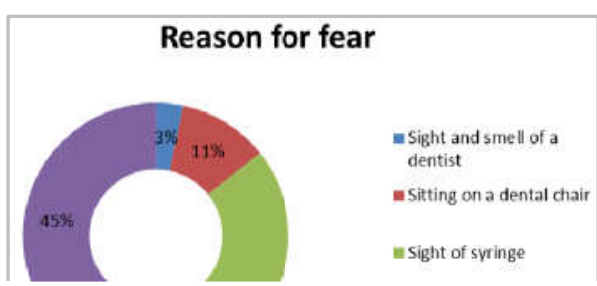

X-ray

\begin{tabular}{cc}
\hline Fear levels & $\begin{array}{c}\text { Number of } \\
\text { people }\end{array}$ \\
\hline None at all & 260 \\
Little & 64 \\
Somewhat & 48 \\
High & 28 \\
Very high & 0 \\
\hline
\end{tabular}

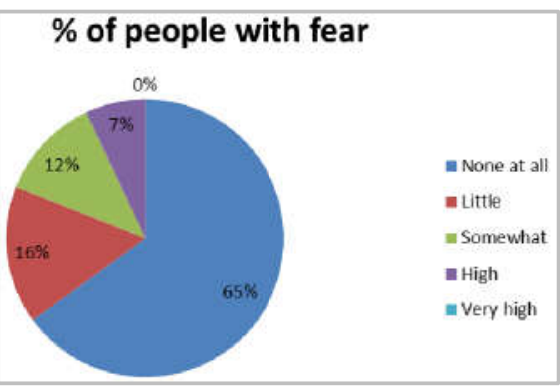




\section{Reason for fear}

\begin{tabular}{cc}
\hline Reason for fear & $\begin{array}{c}\text { Number of } \\
\text { people }\end{array}$ \\
\hline Sight and smell of a dentist & 36 \\
Sitting in a X-ray room & 88 \\
Radiophobia (Fear or of radiations & 100 \\
such as X-ray) & \\
\hline
\end{tabular}

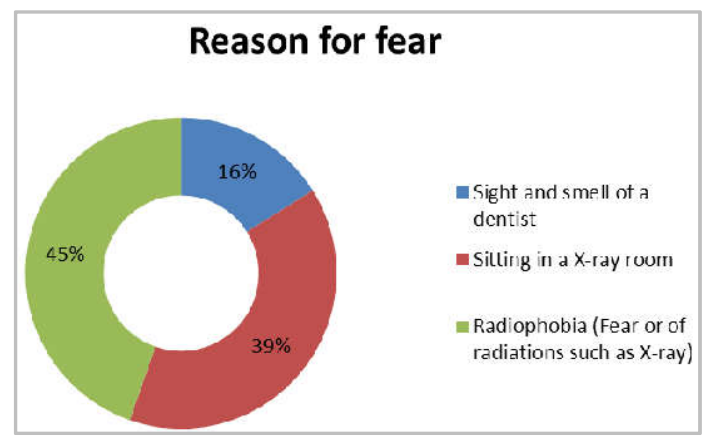

Application of pit and fissure sealants

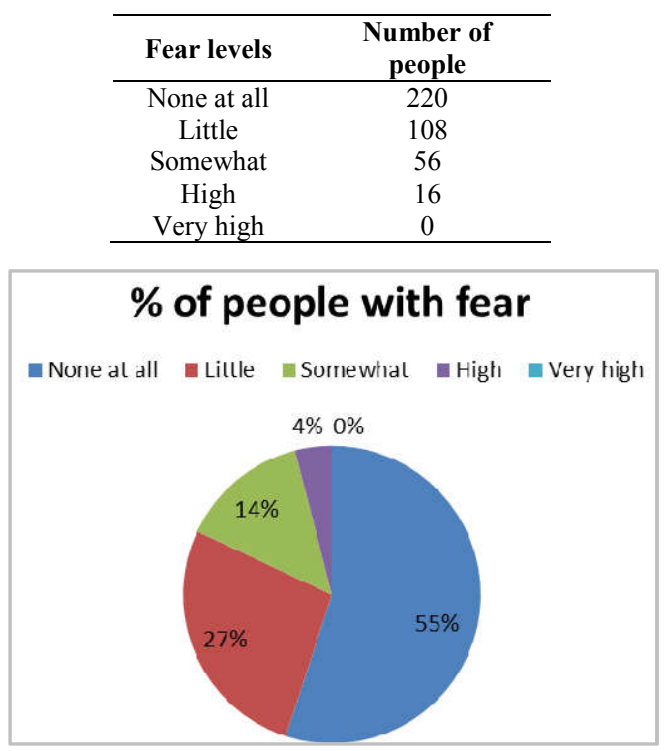

\section{Reason for fear}

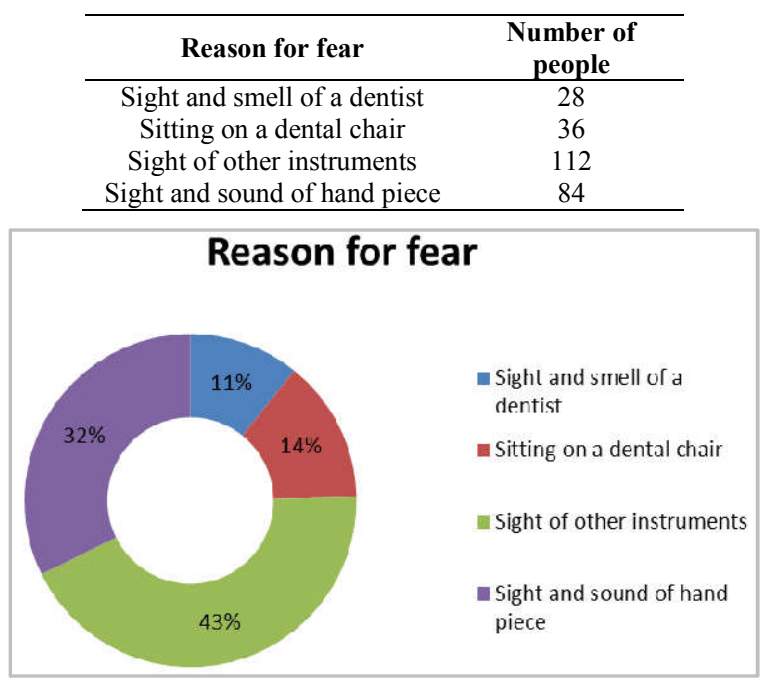

Tooth whitening and fluoride application

\begin{tabular}{cc}
\hline Fear levels & $\begin{array}{c}\text { Number } \\
\text { of people }\end{array}$ \\
\hline None at all & 248 \\
Little & 88 \\
Somewhat & 40 \\
High & 20 \\
Very high & 4 \\
\hline
\end{tabular}

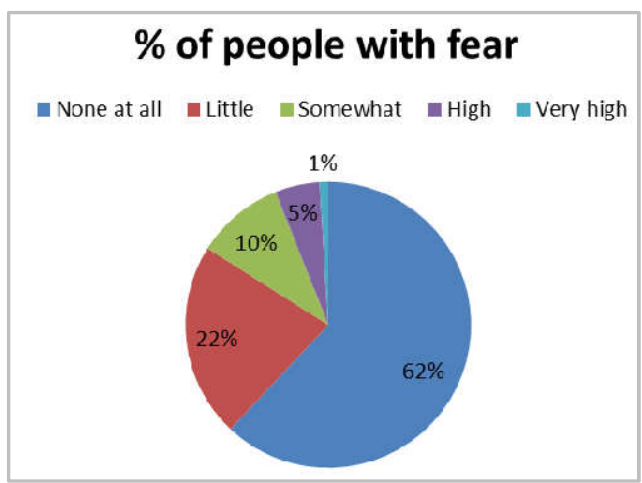

Reason for fear

\begin{tabular}{cc}
\hline Reason for fear & $\begin{array}{c}\text { Number of } \\
\text { people }\end{array}$ \\
\hline Sight and smell of a dentist & 28 \\
$\begin{array}{c}\text { Sitting on a dental chair } \\
\text { Application of topical whitening } \\
\text { paste }\end{array}$ & 44 \\
\hline
\end{tabular}

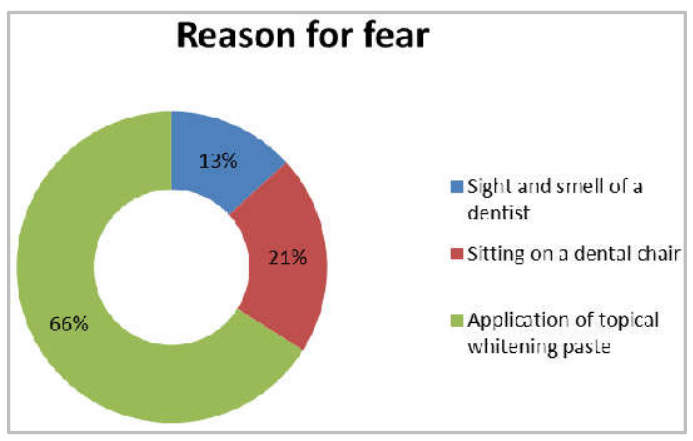

DISCUSSION

This study was conducted to assess the fear levels for different dental treatments. From the survey taken various inferences can be drawn. Scaling had very low fear levels, only a mere $3 \%$ and $2 \%$ showed high and very high fear levels respectively. The main reason for fear being the sensitivity of teeth caused during the treatment. $53 \%$ of the people of the sample polled for this reason during the survey. $20 \%$ of the people of the sample also felt sound of handpiece as major stimuli for fear. Smell and sight of dentists and sitting on a dental chair were too named as reasons for fear. For tooth extraction the fear levels were moderate. Main reasons for fear being sight of blood, syringes and pain. Local anathesia administration, X- rays, Tooth whitening, Dental restorations, dental implants and orthodontic treatment all had very low fear levels.

Importantly, a significant group of people under 17 years along with some elderly felt the sight of a dentist and smell of anesthetic to be major stimuli for dental fearing leading to skipping of appointments and poor oral health. 
Also sight of syringe, forceps and other specialized instruments like spreader were found to evoke fear among the patients. Hence, to provide comfortable treatment to patients and to on general improve public oral health it is absolutely vital for dentists to know the stimuli that evoke fear and accordingly carry out the procedure. For example, while syringes and other dental instruments maybe kept hidden from patients sight. Improvements in the dental handpiece may be made inorder to reduce the sound. Usage of scented antiseptics can aslo is encouraged. Therefore, if managed properly dental fear can be significantly reduced which indirectly may lead better public oral health.

\section{CONCLUSION}

Dental fear is common issue among the general public which may stimulate the patient to skip appointments and behave erratically during the treatment. Dentists shouldn't misinterpret such behavior. Considering the prevalence of dental fear among the population it is vital for a dentist to be familiar with the reasons or stimuli that evoke fear among the patients in order to establish a successful practice.

\section{Reference}

1. Berggren, Ulf, and GunnellMeynert. "Dental fear and avoidance: causes, symptoms, and consequences." The Journal of the American Dental Association 109.2 (1984): 247-251.
2. Kleinknecht, Ronald A., and Douglas A. Bernstein. "The assessment of dental fear." Behavior Therapy 9.4 (1978): 626-634.

3. Gatchel, Robert J., et al. "The prevalence of dental fear and avoidance: a recent survey study." Journal of the American Dental Association (1939)107.4 (1983): 609610.

4. Kleinknecht, Ronald A., et al. "Factor analysis of the dental fear survey with cross-validation." Journal of the American Dental Association (1939) 108.1 (1984): 59.

5. Moore, Rod, IngerBrødsgaard, and HerlufBirn. "Manifestations, acquisition and diagnostic categories of dental fear in a self-referred population." Behaviour Research and Therapy 29.1 (1991): 51-60.

6. Klingberg, Gunilla. "Dental fear and behavior management problems in children. A study of measurement, prevalence, concomitant factors, and clinical effects." Swedish dental journal. Supplement 103 (1994): 1-78.

7. Hakeberg, Magnus, UlfBerggren, and Sven G. Carlsson. "Prevalence of dental anxiety in an adult population in a major urban area in Sweden." Community Dentistry and Oral Epidemiology 20.2 (1992): 97-101.

\section{How to cite this article:}

Suhas Manoharan and Jayalakshmi (2017) ' Fear Levels For Different Dental Procedures Among General Population', International Journal of Current Advanced Research, 06(04), pp. 3139-3143.

DOI: http://dx.doi.org/10.24327/ijcar.2017.3143.0204 